\title{
Shear bond strength and adhesive remnant index of orthodontic brackets bonded to enamel using adhesive systems mixed with $\mathrm{TiO}_{2}$ nanoparticles
}

\author{
Mohammad Behnaz¹,2, Kazem Dalaie², Hoori Mirmohammadsadeghi², Hamed Salehi³, Vahid Rakhshan³, Farzin Aslani²
}

DOI: https://doi.org/10.1590/2177-6709.23.4.43.e1-7.onl

Introduction: It is recently suggested that titanium dioxide $\left(\mathrm{TiO}_{2}\right)$ nanoparticles can be added to bracket luting agents in order to reduce bacterial activity and protect the enamel. However, it is not known if this addition can affect the shear bond strength (SBS) below clinically acceptable levels. Therefore, this study examined this matter within a comprehensive setup. Methods: This in vitro experimental study was conducted on 120 extracted human premolars randomly divided into four groups ( $\mathrm{n}=30)$ : in groups 1 and 2, Transbond XT light-cured composite with or without $\mathrm{TiO}_{2}$ was applied on bracket base; in groups 3 and 4, Resilience light-cured composite with or without $\mathrm{TiO}_{2}$ was used. Brackets were bonded to teeth. Specimens in each group $(\mathrm{n}=30)$ were divided into three subgroups of $10 \mathrm{each}$; then incubated at $37^{\circ} \mathrm{C}$ for one day, one month, or three months. The SBS and adhesive remnant index (ARI) were calculated and compared statistically within groups. Results: The SBS was not significantly different at one day, one month or three months $(p>0.05)$ but composites without $\mathrm{TiO}_{2}$ had a significantly higher mean SBS than composites containing $\mathrm{TiO}_{2}(p<0.001)$. The SBS of Transbond $\mathrm{XT}$ was significantly higher than that of Resilience $(p<0.001)$. No significant differences were noted in ARI scores based on the type of composite or addition of $\mathrm{TiO}_{2}(p>0.05)$. Conclusions: Addition of $\mathrm{TiO}_{2}$ nanoparticles to Transbond XT decreased its SBS to the level of SBS of Resilience without $\mathrm{TiO}_{2}$; thus, $\mathrm{TiO}_{2}$ nanoparticles may be added to Transbond XT composite for use in the clinical setting.

Keywords: Titanium dioxide. Nanoparticles. Orthodontic brackets. Shear bond strength.

Introdução: recentemente, sugeriu-se que nanopartículas de dióxido de titânio $\left(\mathrm{TiO}_{2}\right)$ poderiam ser adicionadas ao cimento adesivo para reduzir a atividade bacteriana e proteger o esmalte. Entretanto, não se sabe se esse acréscimo pode reduzir a resistência adesiva ao cisalhamento (RAC) a níveis inferiores aos clinicamente aceitáveis. Assim, o presente estudo examinou essa questão dentro de um contexto abrangente. Métodos: esse estudo experimental in vitro foi realizado em 120 pré-molares humanos, aleatoriamente divididos em quatro grupos $(\mathrm{n}=30)$. Nos grupos $1 \mathrm{e} 2$, o adesivo fotopolimerizável Transbond XT com e sem $\mathrm{TiO}_{2}$ foi aplicado na base do braquete. Nos grupos 3 e 4, utilizou-se o adesivo fotopolimerizável Resilience com e sem $\mathrm{TiO}_{2}$. Os braquetes foram colados aos dentes e as amostras de cada grupo $(n=30)$ foram divididas em três subgrupos de dez amostras cada, as quais foram incubadas a $37^{\circ} \mathrm{C}$ por, respectivamente, um dia, um mês e três meses. A RAC e o índice de adesivo remanescente (IAR) foram calculados e estatisticamente comparados entre os grupos. Resultados: a RAC não apresentou diferença significativa após um dia, um mês ou três meses $(p>0,05)$, mas os adesivos sem $\mathrm{TiO}_{2}$ apresentaram uma RAC média significativamente mais elevada do que os adesivos que continham $\mathrm{TiO}_{2}(p<0,001)$. A RAC do Transbond XT foi significativamente mais elevada do que a do Resilience $(p<0,001)$. Não foram observadas diferenças significativas nos IARs, seja para o tipo de adesivo ou para a adição de $\mathrm{TiO}_{2}$ $(p>0,05)$. Conclusões: a adição de nanopartículas de $\mathrm{TiO}_{2}$ ao Transbond $\mathrm{XT}$ reduziu sua $\mathrm{RAC}$ a níveis semelhantes aos da $\mathrm{RAC}$ do Resilience $\mathrm{TiO}_{2}$. Assim, as nanopartículas de $\mathrm{TiO}_{2}$ podem ser acrescentadas ao adesivo Transbond XT para a aplicação clínica.

Palavras-chave: Óxido de titânio. Nanopartículas. Braquetes ortodônticos. Resistência adesiva ao cisalhamento.

${ }^{1}$ Shahid Beheshti University of Medical Sciences, Research Institute of Dental Sciences, Dentofacial Deformities Research Center (Tehran, Iran).

${ }^{2}$ Shahid Beheshti University of Medical Sciences, School of Dentistry,

Department of Orthodontic (Tehran, Iran).

${ }^{3}$ Private practice (Tehran, Iran).

» The authors report no commercial, proprietary or financial interest in the products or companies described in this article.

Submitted: May 18, 2017 - Revised and accepted: December 06, 2017
How to cite: Behnaz M, Dalaie K, Mirmohammadsadeghi H, Salehi H, Rakhshan V, Aslani F. Shear bond strength and adhesive remnant index of orthodontic brackets bonded to enamel using adhesive systems mixed with $\mathrm{TiO}_{2}$ nanoparticles. Dental Press J Orthod. 2018 July-Aug;23(4):43.e1-7. doi: https://doi.org/10.1590/2177-6709.23.4.43.e1-7.onl

Contact address: Farzin Aslani

Shahid Beheshti University of Medical Sciences, Department of Orthodontics, School of Dentistry - Velenjak, Tehran, Iran - E-mail: dr.farzin.aslani@gmail.com 


\section{INTRODUCTION}

Orthodontic brackets should endure masticatory forces, by proper adhesion to the enamel, which is reflected in vitro by shear bond strength (SBS). ${ }^{1,2}$ Loosely bonded brackets might dislodge or break, ${ }^{3}$ exerting extra expenses to the clinician and patient in terms of financial, time, and enamel damage (caused by resin removal methods before bonding of new brackets). ${ }^{3-6}$ Therefore, attempts have been made to improve the characteristics of composite resins used to bond orthodontic brackets. Currently micro-filled, micro-hybrid, and flowable composites are mainly used for orthodontic bracket bonding. However, commonly used orthodontic composites often have high polymerization shrinkage, low compressive and tensile strengths, low fracture strength and poor marginal seal. ${ }^{7}$ Nano-composites are the latest technology in the field of restorative composites. Due to the nanometer scale size of their filler particles ( 0.1 to $100 \mathrm{~nm})$, they have very high filler content, which improves their polymerization shrinkage, compressive and tensile strengths, fracture strength and marginal seal, compared to other composites. ${ }^{8}$

Despite all the material improvements, orthodontic brackets still accumulate bacterial plaque. Microbial toxins, enzymes, and acidic byproducts can result in formation of white spots or caries, gingival inflammation, periodontal problems, and increased metal ion release. ${ }^{9-16}$ Orthodontic treatment might cause enamel demineralization or formation of white spot lesions around orthodontic brackets in many orthodontic patients. ${ }^{17-22}$ This is especially important in Orthodontics when many patients cannot effectively maintain a perfect oral hygiene. ${ }^{14}$ Various methods and materials including fluoride or antibacterial agents have been proposed to reduce such side effects. ${ }^{15,18,22-25}$ Nanotechnology is employed in dental materials to improve mechanical properties and develop antimicrobial influences. ${ }^{21,25,26}$ Some composite fillers such as $\mathrm{TiO}_{2}$ have antibacterial properties, and their addition to composites may promote dental health. ${ }^{22}$ Titanium dioxide is an inorganic filler, which is non-toxic and biocompatible, and has optimal antibacterial, optical and electrical properties. ${ }^{27}$ Nanoparticles of $\mathrm{TiO}_{2}$ have proper mechanical, photocatalytic, and antimicrobial characteristics; also they are available in different crystalline formats and sizes, and are believed to be proper for addition into dental materials. ${ }^{14,26}$ Proper antibacterial effects of $\mathrm{TiO}_{2}$ nanoparticles have been previously confirmed. ${ }^{14,15,22,28,29}$ Therefore, its incorporation into bracket adhesives is suggested.

However, it is not known whether the addition of such nanoparticles to the luting agent might or might not disrupt the bond strength, since the literature on this matter is scarce and controversial. To our knowledge, there are only three studies in this regard. Poosti et $\mathrm{al}^{22}$ compared the SBS of two groups of brackets bonded using a light-cure composite with and without $\mathrm{TiO}_{2}$ nanoparticles, and found no significant SBS differences after only 1 day of incubation. ${ }^{22}$ On the other hand, Reddy et al ${ }^{14}$ compared SBS values obtained using luting agents with or without nanoparticles of $\mathrm{TiO}_{2}$ (and without any aging or incubation), and showed a significant 30\% decrease in the SBS after $\mathrm{TiO}_{2}$ incorporation. Felemban and Ebrahim ${ }^{1}$ reported in 2017 that addition of $\mathrm{ZrO}_{2}-\mathrm{TiO}_{2}$ nanoparticles to orthodontic adhesive might improve compressive, tensile, and shear bond strengths of orthodontic brackets. Since studies in this regard are few, this research was conducted. Its aim was to assess the effect of addition of $\mathrm{TiO}_{2}$ nanoparticles to orthodontic composites on the SBS of orthodontic brackets to enamel and the adhesive remnant index (ARI) scores in 120 human premolars.

\section{MATERIAL AND METHODS \\ Preparation of the samples}

This in vitro, experimental study was conducted on 120 freshly extracted sound human premolars, which had been extracted for orthodontic purposes. The teeth were stored in $0.5 \%$ chloramine $\mathrm{T}$ solution at room temperature. The inclusion criteria were freshly extracted sound human premolars, which had not been subjected to any chemical treatment (such as bleaching or exposure to alcohol) prior to extraction. The exclusion criteria were presence of defects, cracks or caries.

First, in a pilot study, the SBS of anatase and rutile mineral forms of $\mathrm{TiO}_{2}$ nanoparticles was measured, and anatase $\mathrm{TiO}_{2}$ nanoparticles were selected for use in this experiment due to having higher SBS.

Anatase $\mathrm{TiO}_{2}$ nanoparticles in $0.1 \mathrm{wt} \%$ concentration were added to composites in a dark room after being weighed by a digital scale and mixed by a stirrer to produce a homogenous blend. To ensure that a homogenous blend was obtained, the mixture was inspected under an electron microscope (KYKYEM3200, USA, Figs 1 and 2). 


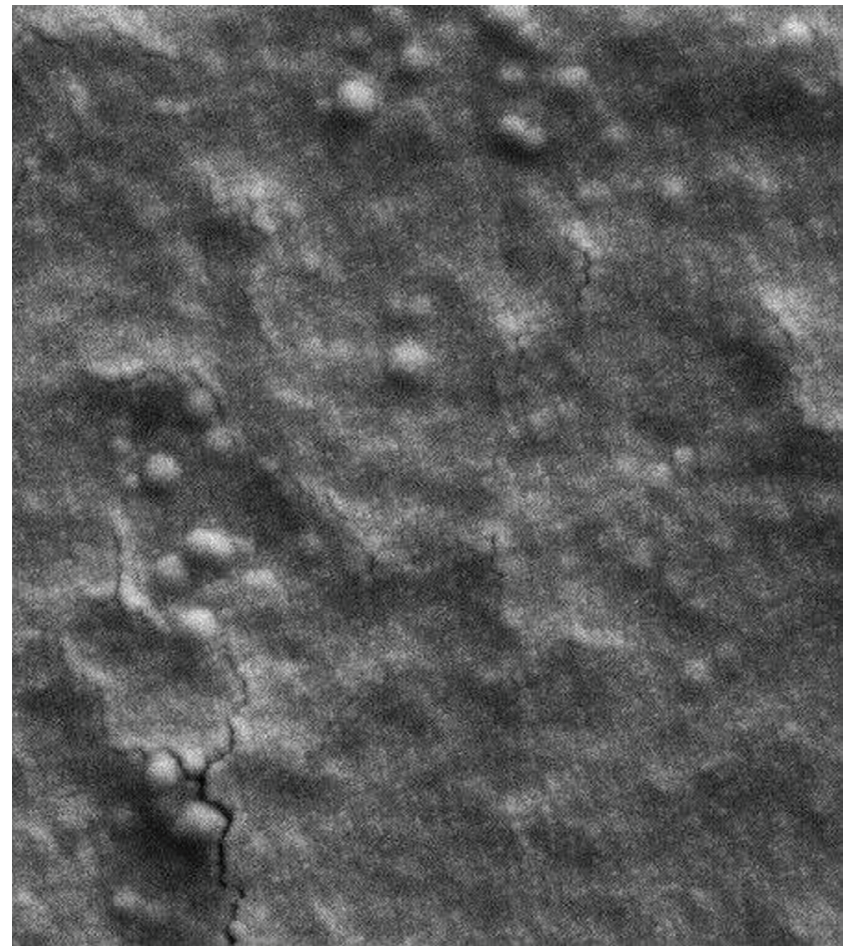

Figure 1 - An example of Transbond $\mathrm{XT}+\mathrm{TiO}_{2}$.

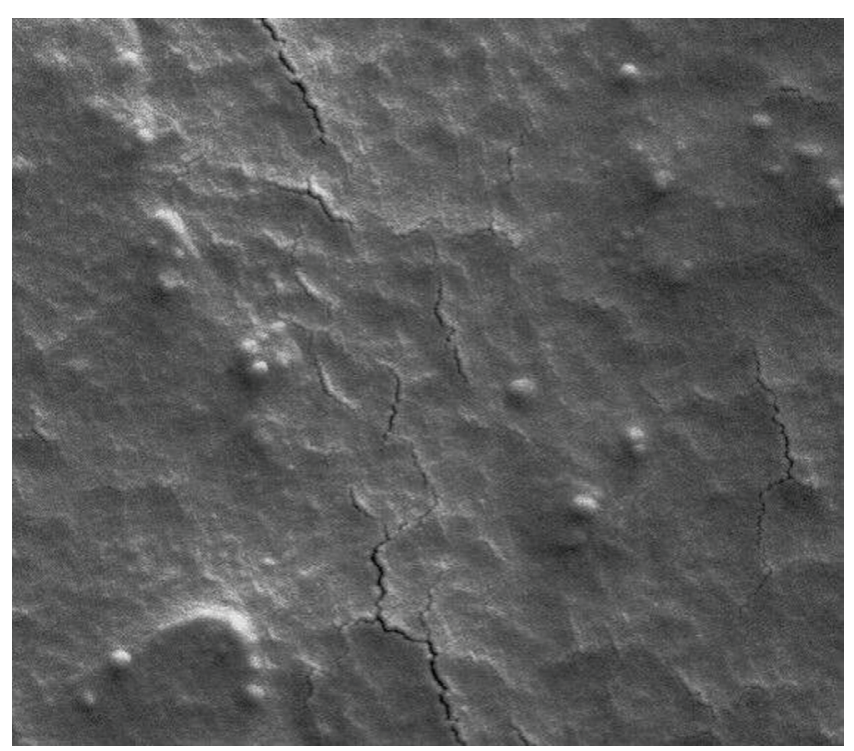

Figure 2 - An example of Resilience $+\mathrm{TiO}_{2}$

The teeth were vertically mounted in auto-polymerizing acrylic blocks. The buccal surface of tooth crown was polished using fluoride-free pumice paste, and it was rinsed and dried. The buccal enamel was etched with 37\% phosphoric acid gel for 20 seconds, rinsed from a $10-15 \mathrm{~cm}$ distance for 40 seconds and was completely dried with oil- and moisture-free air blow to obtain the chalky white appearance of enamel.

\section{Groups}

Eventually, the samples were randomly divided into four groups as follows:

" Group one (Transbond XT): Transbond XT primer (3M Unitek, Monrovia, CA, USA) was applied as a thin coat on the etched enamel, spread on the surface by gentle air spray from a $15 \mathrm{~cm}$ distance, and cured for 10 seconds. Transbond XT composite (3M Unitek) was applied on bracket base (American Orthodontics, Sheboygan, USA). The bracket was placed on the middle third of the buccal enamel surface. Adequate pressure was applied by an explorer to the slot, in order to adapt the bracket to the tooth surface.

» Group two (Transbond XT plus $\mathrm{TiO}_{2}$ ): Transbond $\mathrm{XT}$ primer was applied as a thin coat on the etched enamel and cured for 10 seconds. Transbond $\mathrm{XT}$ plus $\mathrm{TiO}_{2}$ composite was applied on the bracket base, and the bracket was adapted to the enamel surface as in group one.

» Group three (Resilience): Resilience primer (Ortho Technology, Florida, USA) was applied as a thin coat on the etched enamel and cured for 10 seconds. Resilience composite (Ortho Technology, Lutz, Florida, USA) was placed on the bracket base, and the bracket was adapted to the enamel surface as in group one.

» Group four (Resilience plus $\mathrm{TiO}_{2}$ ): Resilience primer was applied as a thin coat on the etched enamel and cured for 10 seconds. Resilience composite plus $\mathrm{TiO}_{2}$ nanoparticles was placed on the bracket base and the bracket was adapted to the enamel surface as in group one.

Excess composite in all four groups was removed by the sharp tip of a scaler; all samples were light-cured for 10 seconds from the mesial, 10 seconds from the distal, 10 seconds from the gingival and 10 seconds from the occlusal surface using a light curing unit (Woodpecker Guilin, Guangxi, China) with a light intensity of $1000 \mathrm{~mW} / \mathrm{cm}^{2}$. Also, the light-curing unit was calibrated by a radiometer every 10 minutes, to ensure equal intensity of light for all samples.

\section{Evaluation of shear bond strength}

Afterwards, the teeth were placed in deionized distilled water and incubated at $37^{\circ} \mathrm{C}$ to allow water sorption. At the designated time points (one day, one month, and three months), the teeth were placed on the jig of an Instron machine (Janke \& Kuknek, IKA-Laborte Chnik, Germany). The stainless steel blade of the Instron machine had $4.0 \mathrm{~mm}$ length and applied the load to the 
bracket at a crosshead speed of $1 \mathrm{~mm} /$ minute. The SBS was calculated in MegaPascal (MPa) unit by dividing the shear load by surface area of the bracket base.

\section{Assessment of Adhesive Remnant Index}

After debonding, the ARI score was calculated based on the following scoring system under a $10 \times$ stereomicroscope (Olympus, Japan):

"Score zero: Indicated absence of composite remnants on the enamel surface.

» Score one: Less than $50 \%$ of composite remaining on the enamel surface.

" Score two: More than 50\% of composite remaining on the enamel surface.

" Score three: The entire composite remained on the enamel surface with a clear impression of the bracket base on the remaining composite.

\section{Statistical analysis}

The effects of time, type of composite and presence/ absence of $\mathrm{TiO}_{2}$ nanoparticles on the SBS of brackets to enamel were analyzed using three-way analysis of variance (ANOVA). Also, comparisons of the groups in terms of ARI scores were made using the Mann-Whitney test. Changes in ARI scores over time (based on the duration of incubation of samples) were analyzed using the Kruskal-Wallis test of SPSS software (version 20, IBM, Armonk, NY, USA). Level of significance was predetermined as $\leq 0.05$.

\section{RESULTS}

The mean and standard deviation (SD) of SBS based on the time of incubation, type of composite and pres- ence/absence of $\mathrm{TiO}_{2}$ nanoparticles in the composites are presented in Table 1. The highest SBS was found in Transbond XT composite $(145.73 \pm 3.87 \mathrm{MPa})$ followed by Resilience $(125.59 \pm 3.37 \mathrm{MPa})$ without $\mathrm{TiO}_{2}$ nanoparticles. The lowest SBS was noted in Resilience plus $\mathrm{TiO}_{2}$ $\left(77.75 \pm 2.33 \mathrm{MPa}\right.$ ) followed by Transbond $\mathrm{XT}$ plus $\mathrm{TiO}_{2}$ $(123.92 \pm 3.17 \mathrm{MPa})$ groups. Normal distribution of SBS data was ensured by the Kolmogorov-Smirnov test. Since the data were normally distributed and considering the equality of variances confirmed by Levene's test, three-way ANOVA was used to compare the SBS values in the four groups. The three-way ANOVA revealed no significant difference in SBS of the groups over time ( $p=0.94)$; however, the mean SBS was significantly higher in the groups of pure composites without $\mathrm{TiO}_{2}$ nanoparticles compared to the value in composites containing $\mathrm{TiO}_{2}(p<0.001)$. Also, the mean SBS of Transbond XT composite was significantly higher than that of Resilience composite $(p<0.001)$ and the interaction effect of type of composite and presence/absence of $\mathrm{TiO}_{2}$ on SBS was statistically significant $(p<0.001)$. In Transbond XT composite without $\mathrm{TiO}_{2}$, the mean SBS value was about 20 units higher than that in Transbond XT containing $\mathrm{TiO}_{2}$. This difference in Resilience groups was 40 units. The other interaction effects were not significant ( $p>0.05$ for all comparisons).

Table 2 shows the mean ARI scores in the four groups. According to the results of Mann-Whitney $U$ test, no significant differences were noted in terms of ARI scores based on the type of composite used or presence/absence of $\mathrm{TiO}_{2}$ nanoparticles $(p=0.43)$. The ARI scores did not change significantly over time according to the results of the KruskalWallis test $(p=0.19)$.

Table 1 - Statistics of shear bond strength (MPa) at different time points in the four groups

\begin{tabular}{|c|c|c|c|c|c|c|c|}
\hline Brand & $\mathrm{THO}_{2}$ & Aging (day) & Mean & SD & SE & \multicolumn{2}{|c|}{$95 \% \mathrm{Cl}$} \\
\hline \multirow{6}{*}{ Transbond X } & \multirow{3}{*}{ No } & 1 & 147.44 & 6.28 & 1.99 & 142.95 & 151.93 \\
\hline & & 30 & 146.08 & 3.95 & 1.25 & 143.25 & 148.91 \\
\hline & & 90 & 143.66 & 9.41 & 2.98 & 136.93 & 150.39 \\
\hline & \multirow{3}{*}{ Yes } & 1 & 126.43 & 5.93 & 1.88 & 122.19 & 130.67 \\
\hline & & 30 & 120.99 & 5.84 & 1.85 & 116.81 & 125.17 \\
\hline & & 90 & 124.33 & 5.09 & 1.61 & 120.69 & 127.97 \\
\hline \multirow{6}{*}{ Resilience } & \multirow{3}{*}{ No } & 1 & 125.62 & 6.65 & 2.10 & 120.86 & 130.38 \\
\hline & & 30 & 124.12 & 6.83 & 2.16 & 119.23 & 129.01 \\
\hline & & 90 & 127.05 & 4.26 & 1.35 & 124.00 & 130.10 \\
\hline & \multirow{3}{*}{ Yes } & 1 & 74.25 & 5.51 & 1.74 & 70.31 & 78.19 \\
\hline & & 30 & 78.66 & 3.62 & 1.14 & 76.07 & 81.25 \\
\hline & & 90 & 80.35 & 2.58 & 0.82 & 78.50 & 82.20 \\
\hline
\end{tabular}

$\mathrm{SD}=$ standard deviation; $\mathrm{SE}=$ standard error; $\mathrm{Cl}=$ confidence interval 
Table 2 - The mean ARI scores in the four groups.

\begin{tabular}{|c|c|c|c|}
\hline Type of composite & Time & Mean & Score \\
\hline \multirow{3}{*}{ Transbond XT } & Three months & $70 \%$ & 2 \\
\hline & One month & $100 \%$ & 3 \\
\hline & One day & $63 \%$ & 2 \\
\hline \multirow{3}{*}{ Transbond XT $+\mathrm{TiO}_{2}$} & Three months & $55 \%$ & 2 \\
\hline & One month & $100 \%$ & 3 \\
\hline & One day & $77 \%$ & 2 \\
\hline \multirow{3}{*}{ Resilience } & Three months & $100 \%$ & 3 \\
\hline & One month & $60.7 \%$ & 2 \\
\hline & One day & $95 \%$ & 2 \\
\hline \multirow{3}{*}{ Resilience $+\mathrm{TiO}_{2}$} & Three months & $67 \%$ & 2 \\
\hline & One month & $80 \%$ & 2 \\
\hline & One day & $90 \%$ & 2 \\
\hline
\end{tabular}

\section{DISCUSSION}

An acceptable bracket bonding system must be able to resist destructive forces applied by orthodontic wires as well as the loads applied in the oral cavity. ${ }^{30,31}$ The present results showed that addition of $\mathrm{TiO}_{2}$ nanoparticles to orthodontic composites significantly decreased the mean SBS of both Transbond XT and Resilience composites. Also, the mean SBS did not significantly change over time. The mean SBS was significantly higher in composites without $\mathrm{TiO}_{2}$ compared to composites containing $\mathrm{TiO}_{2}$. In contrast to the findings of the current study, Felemban and Ebrahim ${ }^{1}$ reported that adding $\mathrm{ZrO}_{2}-\mathrm{TiO}_{2}$ nanoparticles might improve shear bond strength (together with tensile and compressive strengths). Furthermore, Poosti et a ${ }^{22}$ assessed the SBS of Transbond XT with and without addition of $1 \% \mathrm{TiO}_{2}$ nanoparticles (less than $50 \mathrm{~nm}$ in size) and found no significant difference in SBS of this composite with and without $\mathrm{TiO}_{2}$ at 24 hours. ${ }^{22}$ However, Reddy et al ${ }^{14}$ reported a significant $30 \%$ decrease in the SBS obtained using composites containing $\mathrm{TiO}_{2}$. A study on the addition of copper nanoparticles to orthodontic luting agents reported an increase in bond strength after nanoparticle addition. ${ }^{23}$ Blöcher et a ${ }^{32}$ evaluated the effect of addition of nano and microparticles of silver to orthodontic adhesive, and reported no significant change in SBS. Akhavan et $\mathrm{a}^{33}$ evaluated the effect of addition of silver nanoparticles/hydroxyapatite to Transbond XT orthodontic adhesive on SBS to enamel and found that addition of $1 \%$ to $5 \%$ silver nanoparticles/hydroxyapatite increased the SBS of adhesive, while addition of $10 \%$ silver nanoparticles/hydroxyapatite had no favorable effect on bond strength, compared to the control group. ${ }^{33}$ These differences can be attributed to various methodological variations, for instance: small sample sizes were small and might disallow identification of differences; moreover, particle sizes were not standardized across studies. It is possible that particles larger than a certain threshold might interfere with adhesive bonds more considerably while smaller particles might not. Additionally, different durations of aging procedures might affect results. Furthermore, different results pertaining to different types and brands of adhesives are not fully generalizable to other types and brands. Hence, their standardization would allow a better comparison of the effect of particle addition. ${ }^{34,35}$

In bracket bonding, in contrast to restorative treatments, very high bond strength is not always favorable, since the enamel surface would be damaged at the time of bracket debonding. ${ }^{6} \mathrm{~A}$ minimum SBS of about 6 to 10MPa might suffice to hold orthodontic brackets in place. , $^{2,85-38}$ Increasing the SBS to $13 \mathrm{MPa}$ might increase the likelihood of cohesive failures and damage to ceramic restorations. ${ }^{39}$

Depending on brands in use, SBS varied greatly, as addition of $\mathrm{TiO}_{2}$ nanoparticles to Transbond XT composite decreased its bond strength to the level of SBS of Resilience composite without $\mathrm{TiO}_{2}$ in this study. Thus, certain brands of adhesives might pro- 
vide higher bond strengths when needed. Uysal et $\mathrm{al}^{8}$ reported that Transbond XT yielded the highest SBS $(12.6 \pm 4.48 \mathrm{MPa})$ followed by nano-composite $(8.33 \pm 5.16 \mathrm{MPa})$ and nano-ionomer $(6.14 \pm 2.12 \mathrm{MPa})$.

Aging can weaken composite matrix by mechanisms such as swelling it, depleting its free radicals by water sorption or thermal stresses, and hydrolytic degradation of the silane film over fillers. ${ }^{37,40-43}$ However, this study did not show any significant differences between 1, 30, or 90 days of aging. It is possible that $\mathrm{TiO}_{2}$ nanoparticles might have improved resin structure and have reduced the deteriorating effect of aging. There was no study on the effect of aging on SBS of $\mathrm{TiO}_{2}$-incorporated resins, and future studies should evaluate this.

After bracket debonding, removal of resin from enamel side might be clinically favorable, as it might reduce damage caused by bracket debonding procedures. ${ }^{36,37}$ To assess the bracket debonding interface, ARI score is often calculated ${ }^{8}$ Comparison of ARI scores based on the type of composite and presence/absence of $\mathrm{TiO}_{2}$ showed no significant difference in this regard. The ARI scores did not change significantly over time. Uysal et $\mathrm{al}^{8}$ reported no significant difference in ARI scores among Transbond XT composite, Filtek Supreme Plus Universal nano-composite and Ketac ${ }^{\mathrm{TM}}$ N100 light-curing nano-ionomer. Similarly, Akhavan et $\mathrm{al}^{33}$ found no significant difference in ARI scores among 1\%, 5\% and 10\% silver nanoparticles/hydroxyapatite plus Transbond XT primer. In their study, addition of silver nanoparticles/hydroxyapatite to Transbond XT orthodontic adhesive caused no significant difference in ARI scores of the groups. ${ }^{33}$ On the other hand, according to Nagar et al, ${ }^{44}$ ARI scores were not significantly different between the two groups of Transbond XT and nano-ceramic composites, which was in agreement with the current results.

This study was limited by some factors. A sample size calculated based on pilot studies could favor the reliability. Moreover, in vitro experiments of bond strength cannot be generalized to clinical situations where different forces are exerted from various directions over brackets. ${ }^{38}$ In addition, results pertaining to a specific brand of some material cannot be generalized to other brands or formulas. ${ }^{38}$ Some differences exist among tensile, shear and torsional loads; however, shear loads are among the most common and most destructive forces in the oral cavity. ${ }^{30,31}$ Although these are standard tests, they cannot simulate the actual loads applied in the oral environment because the speed of jaw movements during mastication is in the range of $81-100 \mathrm{~mm} / \mathrm{second}$ or $4860-6000 \mathrm{~mm} /$ minute with a frequency of $1.03-1.2 \mathrm{~Hz}$, which is different from the selected crosshead speeds for SBS testing. ${ }^{45}$

\section{CONCLUSIONS}

The addition of $\mathrm{TiO}_{2}$ nanoparticles might reduce SBS, but the adhesion might still be at an acceptable level. Transbond XT and Resilience without $\mathrm{TiO}_{2}$ nanoparticles yielded the highest SBS values, respectively. However, addition of $\mathrm{TiO}_{2}$ nanoparticles to Transbond XT decreased its SBS to the level of SBS of Resilience without $\mathrm{TiO}_{2}$. Thus, $\mathrm{TiO}_{2}$ nanoparticles may be added to Transbond XT composite.

\section{Authors contribution}

Conception or design of the study: MB, HM. Data acquisition, analysis or interpretation: KD, HM, VR. Writing the article: HS. Critical revision of the article: FA. Final approval of the article: VR. Overall responsibility: FA.

\section{REFERENCES}

1. Felemban NH, Ebrahim MI. The influence of adding modified zirconium oxide-titanium dioxide nano-particles on mechanical properties of orthodontic adhesive: an in vitro study. BMC Oral Health. 2017:17:43. Reynolds I. A review of direct orthodontic bonding. Br J Orthod. 1975:2:171-8.

3. Eminkahyagil N, Arman A, Cetinsahin A, Karabulut E. Effect of resin-removal methods on enamel and shear bond strength of rebonded brackets. Angle Orthod. 2006 Mar;76(2):314-21.

4. Mandall NA, Millett DT, Mattick CR, Hickman J, Macfarlane TV, Worthington HV. Adhesives for fixed orthodontic brackets. Cochrane Database Syst Rev. 2003:(2):CD002282.

\footnotetext{
5. Chen CS, Hsu ML, Chang KD, Kuang SH, Chen PT, Gung YW. Failure analysis: enamel fracture after debonding orthodontic brackets. Angle Orthod. 2008 Nov:78(6):1071-7.

6. Khosravanifard B, Nemati-Anaraki S, Nili S, Rakhshan V. Assessing the effects of three resin removal methods and bracket sandblasting on shear bond strength of metallic orthodontic brackets and enamel surface. Orthod Waves. 2011:70(1):27-38.

7. Chalipa J, Akhondi MS, Arab S, Kharrazifard MJ, Ahmadyar M. Evaluation of shear bond strength of orthodontic brackets bonded with nano-filled composites. J Dent (Tehran). 2013 Sept;10(5):461-5.
} 
8. Uysal T, Yagci A, Uysal B, Akdogan G. Are nano-composites and nanoionomers suitable for orthodontic bracket bonding? Eur J Orthod. 2010 Feb;32(1):78-82.

9. Ryu HS, Bae IH, Lee KG, Hwang HS, Lee KH, Koh JT, et al. Antibacterial effect of silver-platinum coating for orthodontic appliances. Angle Orthod. 2012 Jan; 82(1):151-7.

10. Brusca MI, Chara O, Sterin-Borda L, Rosa AC. Influence of different orthodontic brackets on adherence of microorganisms in vitro. Angle Orthod. 2007 Mar;77(2):331-6.

11. Amini F, Shariati M, Sobouti F, Rakhshan V. Effects of fixed orthodontic treatment on nickel and chromium levels in gingival crevicular fluid as a novel systemic biomarker of trace elements: a longitudinal study. Am J Orthod Dentofacial Orthop. 2016 May:149(5):666-72.

12. Rakhshan $H$, Rakhshan $V$. Effects of the initial stage of active fixed orthodontic treatment and sex on dental plaque accumulation: a preliminary prospective cohort study. Saudi J Dent Res. 2015 July; 6(2):86-90

13. van Gastel J, Quirynen M, Teughels W, Pauwels M, Coucke W, Carels C. Microbial adhesion on different bracket types in vitro. Angle Orthod. 2009 Sept;79(5):915-21

14. Reddy AK, Kambalyal PB, Patil SR, Vankhre M, Khan MY, Kumar TR. Comparative evaluation and influence on shear bond strength of incorporating silver, zinc oxide, and titanium dioxide nanoparticles in orthodontic adhesive. J Orthod Sci. 2016 Oct-Dec; 5(4):127-31

15. Ghasemi T, Arash V, Rabiee M, Rajab Nia R, Pour Zare AH, Rakhshan V. Antimicrobial effect, frictional resistance, and surface roughness of stainless steel orthodontic brackets coated with nanofilms of silver and titanium oxide: a preliminary study. Microsc Res Tech. 2017 June; 80(6):599-607.

16. Amini F, Mollaei M, Harandi S, Rakhshan V. Effects of fixed orthodontic treatment on hair nickel and chromium levels: a 6-month prospective preliminary study. Biol Trace Elem Res. 2015 Mar:164(1):12-7.

17. Sallum EJ, Nouer DF, Klein MI, Goncalves RB, Machion L, Wilson Sallum A, et al. Clinical and microbiologic changes after removal of orthodontic appliances. Am J Orthod Dentofacial Orthop. 2004 Sept;126(3):363-6.

18. Yu F, Dong Y, Yu HH, Lin PT, Zhang L, Sun X, et al. Antibacterial activity and bonding ability of an orthodontic adhesive containing the antibacterial monomer 2-methacryloxylethyl hexadecyl methyl ammonium bromide. Sci Rep. 2017;7:41787.

19. Enaia M, Bock N, Ruf S. White-spot lesions during multibracket appliance treatment: a challenge for clinical excellence. Am J Orthod Dentofacial Orthop. 2011 July:140(1):e17-24

20. Chambers C, Stewart S, Su B, Sandy J, Ireland A. Prevention and treatment of demineralisation during fixed appliance therapy: a review of current methods and future applications. Br Dent J. 2013 Nov:215(10):505-11

21. Heravi F, Ramezani M, Poosti M, Hosseini M, Shajiei A, Ahrari F. In Vitro cytotoxicity assessment of an orthodontic composite containing titanium-dioxide nano-particles. J Dent Res Dent Clin Dent Prospects. 2013 Autumn;7(4):192-8.

22. Poosti M, Ramazanzadeh B, Zebarjad M, Javadzadeh P, Naderinasab M, Shakeri MT. Shear bond strength and antibacterial effects of orthodontic composite containing $\mathrm{TiO}_{2}$ nanoparticles. Eur J Orthod. 2013 Oct:35(5):676-9.

23. Argueta-Figueroa L, Scougall-Vilchis RJ, Morales-Luckie RA, OleaMejía OF. An evaluation of the antibacterial properties and shear bond strength of copper nanoparticles as a nanofiller in orthodontic adhesive. Aust Orthod J. 2015 May; 31(1):42-8.

24. Sodagar A, Bahador A, Pourhajibagher M, Ahmadi B, Baghaeian P. Effect of addition of curcumin nanoparticles on antimicrobial property and shear bond strength of orthodontic composite to bovine enamel. J Dent (Tehran). 2016 Sept;13(5):373-82.

25. Mirhashemi A, Bahador A, Kassaee M, Daryakenari G, Ahmad-Akhoundi M, Sodagar A. Antimicrobial effect of nano-zinc oxide and nano-chitosan particles in dental composite used in orthodontics. J Med Bacteriol. 2015:2:1-10.
26. Sun J, Forster AM, Johnson PM, Eidelman N, Quinn G, Schumacher G, et al. Improving performance of dental resins by adding titanium dioxide nanoparticles. Dent Mater. 2011 Oct;27(10):972-82.

27. Macwan D, Dave PN, Chaturvedi S. A review on nano-TiO 2 sol-gel type syntheses and its applications. J Mater Sci. 2011;46:3669-86.

28. Verdier T, Coutand M, Bertron A, Roques C. Antibacterial activity of $\mathrm{TiO}_{2}$ photocatalyst alone or in coatings on E. coli: the influence of methodological aspects. Coatings. 2014;4(3):670-86.

29. Senarathna ULNH, Fernando SSN, Gunasekara TDCP, Weerasekera MM, Hewageegana HGSP, Arachchi NDH, et al. Enhanced antibacterial activity of TiO(2) nanoparticle surface modified with Garcinia zeylanica extract. Chem Cent J. 2017:11:7

30. Büyükyilmaz T, Zachrisson BU. Improved orthodontic bonding to silver amalgam. Part 2. Lathe-cut, admixed, and spherical amalgams with different intermediate resins. Angle Orthod. 1998 Aug:68(4):337-44

31. Cooley RL, McCourt JW, Train TE. Bond strength of resin to amalgam as affected by surface finish. Quintessence Int. 1989 Apr;20(4):237-9

32. Blöcher S, Frankenberger R, Hellak A, Schauseil M, Roggendorf MJ, Korbmacher-Steiner HM. Effect on enamel shear bond strength of adding microsilver and nanosilver particles to the primer of an orthodontic adhesive. BMC Oral Health. 2015:15:42.

33. Akhavan A, Sodagar A, Mojtahedzadeh F, Sodagar K. Investigating the effect of incorporating nanosilver/nanohydroxyapatite particles on the shear bond strength of orthodontic adhesives. Acta Odontol Scand. 2013 Sept;71(5):1038-42.

34. Khosravanifard B, Nemati-Anaraki S, Faraghat S, Sajjadi SH, Rakhshan H, Rakhshan V. Efficacy of 4 surface treatments in increasing the shear bond strength of orthodontic brackets bonded to saliva-contaminated direct composites. J Dent Res Dent Clin Dent Prospects. 2016 Winter:10(1):9-16.

35. Khosravanifard B, Rakhshan V, Saadatmand A. Effects of blood and saliva contamination on shear bond strength of metal orthodontic brackets and evaluating certain methods for reversing the effect of contamination. Orthod Waves. 2010;69:156-63.

36. Khosravanifard B, Nemati-Anaraki S, Nili S, Rakhshan V. Assessing the effects of three resin removal methods and bracket sandblasting on shear bond strength of metallic orthodontic brackets and enamel surface. Orthod Waves. 2011 Mar:70(1):27-38

37. Khosravanifard B, Yazdani R, Rakhshan H, Rakhshan V. The effect of acidulated phosphate fluoride incorporated phosphoric acid etchant on shear bond strength of orthodontic brackets. Dent Res J (Isfahan). 2011 Oct-Dec; 8(4):183-8.

38. Khosravanifard B, Rakhshan V, Araghi S, Parhiz H. Effect of ascorbic acid on shear bond strength of orthodontic brackets bonded with resinmodified glass-ionomer cement to bleached teeth. J Dent Res Dent Clin Dent Prospects. 2012 Spring:6(2):59-64.

39. Thurmond JW, Barkmeier WW, Wilwerding TM. Effect of porcelain surface treatments on bond strengths of composite resin bonded to porcelain. J Prosthet Dent. 1994 Oct;72(4):355-9.

40. Jafarzadeh Kashi TS, Erfan M, Rakhshan V, Aghabaigi N, Tabatabaei FS An in vitro assessment of the effects of three surface treatments on repair bond strength of aged composites. Oper Dent. 2011 NovDec;36(6):608-17.

41. Nassoohi N, Kazemi H, Sadaghiani M, Mansouri M, Rakhshan V. Effects of three surface conditioning techniques on repair bond strength of nanohybrid and nanofilled composites. Dent Res J (Isfahan). 2015 NovDec;12(6):554-61.

42. Powers J, Sakaguchi R, Craig R. Craig's restorative dental materials. New York: Mosby Elsevier; 2006.

43. Rakhshan $V$. Marginal integrity of provisional resin restoration materials: a review of the literature. Saudi J Dent Res. 2015;6:33-40

44. Nagar N, Vaz AC. Comparison of shear bond strengths of conventional orthodontic composite and nano-ceramic restorative composite: an in vitro study. Indian J Dent Res. 2013 Nov-Dec:24(6):713-8.

45. Buschang PH, Hayasaki H, Throckmorton GS. Quantification of human chewing-cycle kinematics. Arch Oral Biol. 2000 June;45(6):461-74. 